\title{
Neutrophil-to-Lymphocyte Ratio as a Predictor of Postoperative Recurrence and Prognosis in Oesophageal Squamous Cell Carcinoma
}

\author{
MANATO OHSAWA, YOICHI HAMAI, MANABU EMI, YUTA IBUKI, TOMOAKI KUROKAWA, \\ TORU YOSHIKAWA, RYOSUKE HIROHATA, NAO KITASAKI and MORIHITO OKADA
}

Department of Surgical Oncology, Hiroshima University, Hiroshima, Japan

\begin{abstract}
Background: Trimodal therapy is frequently used for patients with locally advanced, resectable oesophageal cancer. However, it does not provide a satisfactory prognosis. The neutrophil-to-lymphocyte ratio (NLR) is an important indicator of patients' inflammatory and immune statuses. We investigated the prognostic role of NLR values obtained at different treatment stages in patients with oesophageal squamous cell carcinoma. Patients and Methods: We evaluated the correlation between NLR values or their change and prognosis at each treatment point (before chemoradiotherapy; before surgery; and at 14 days, and 1 and 2 months postoperatively) in 163 patients with oesophageal squamous cell carcinoma who underwent oesophagectomy after neoadjuvant chemoradiotherapy from April 2003 to August 2018. The outcomes studied were overall (OS) and relapse-free (RFS) survival. Results: The NLR at 1 month postoperatively showed the strongest correlation with prognosis, with an optimal cut-off value of 4.5 (area under the curve $=0.7878 ; 95 \%$ confidence interval $=0.70-0.85 ; p<0.0001)$. Univariate and multivariate analyses showed that NLR $\geq 4.5$ was a significant factor for both RFS (hazard ratio=4.44, 95\% confidence interval=2.69-7.34) and OS (hazard ratio=3.88, 95\% confidence interval=2.38-6.32). Furthermore, NLR significantly stratified patients for the RFS and OS regardless of the pathological response (complete/non-complete response)
\end{abstract}

Correspondence to: Yoichi Hamai, Department of Surgical Oncology, Research Institute for Radiation Biology and Medicine, Hiroshima University, 1-2- 3-Kasumi, Minami-ku, Hiroshima City, Hiroshima 734-0037, Japan. Tel.: +81 822575869, Fax: +81 822567109, e-mail: yyhamai@hiroshima-u.ac.jp

Key Words: Neutrophil-to-lymphocyte ratio, oesophageal squamous cell carcinoma, trimodal therapy, prognosis.

This article is an open access article distributed under the terms an conditions of the Creative Commons Attribution (CC BY-NC-ND) 4.0 international license (https://creativecommons.org/licenses/by-nc-nd/4.0). and postoperative complications (Clavien-Dindo grade $<I I I a l \geq$ IIIa). Conclusion: NLR measurement at 1 month postoperatively correlated with prognosis and was also a useful predictor of recurrence. Patients with high NLRs need more rigorous followup as they constitute a high-risk group. Postoperative adjuvant therapy may also be considered for such patients.

Trimodal therapy, comprising neoadjuvant chemoradiotherapy (NCRT) followed by surgery, is frequently administered for local control and to improve the survival rate of patients with locally advanced, resectable oesophageal cancer (EC). Although the survival rates of patients with EC have been improved by multidisciplinary treatment, some patients still experience early postoperative recurrence and cancer-related death even after treatment with NCRT and surgery. The reported 5-year survival rate is $40-60 \%$ for patients with locally advanced EC after trimodal therapy, and the prognosis is not $\operatorname{good}(1-3)$.

Whether postoperative recurrence can be reduced with EC treatment remains a major issue. With the recent development of immune checkpoint inhibitors, the therapeutic strategy for EC has dramatically changed, and further enhancement of adjuvant therapy and improvement in prognosis are expected (4). Hence, it is important to evaluate the treatment response and immune status of individual patients because they may provide information on suitable targets for intensified adjuvant therapy.

The neutrophil-to-lymphocyte ratio (NLR) is an important indicator of a patient's inflammatory and immune statuses (57). A change in NLR may reflect broader changes in the tumour microenvironment, and an elevated NLR in association with many solid tumours has been correlated with reduced survival $(8,9)$. Several studies have been conducted on evaluation of the preoperative NLR. In contrast, there are few reports on its evaluation after surgery (10). A patient's immune status and cancer progression change over time and with therapeutic intervention. Pre- and perioperative evaluation of NLR as an assessment of treatment responsiveness is a useful 
Table I. Clinicopathologic features of patients $(N=163)$.

\begin{tabular}{|c|c|c|}
\hline Parameter & & Value \\
\hline Age, years & Mean \pm SD & $63.4 \pm 7.9$ \\
\hline \multirow[t]{2}{*}{ Gender, n (\%) } & Male & $137(84.0 \%)$ \\
\hline & Female & $26(16.0 \%)$ \\
\hline \multirow{2}{*}{ Performance status, n (\%) } & 0 & $140(85.9 \%)$ \\
\hline & 1 & $23(14.1 \%)$ \\
\hline \multirow{2}{*}{ Tumour markers (mean $\pm \mathrm{SD}$ ), ng/ml } & $\mathrm{SCC}$ & $1.9 \pm 2.1$ \\
\hline & CEA & $2.7 \pm 2.0$ \\
\hline \multirow[t]{3}{*}{ Primary tumour location, $\mathrm{n}(\%)$} & Upper & $34(20.8 \%)$ \\
\hline & Middle & $80(49.1 \%)$ \\
\hline & Lower & $49(30.1 \%)$ \\
\hline \multirow[t]{4}{*}{ Clinical T-stage, $\mathrm{n}(\%)^{\mathrm{a}}$} & cT1 & $2(1.2 \%)$ \\
\hline & $\mathrm{cT} 2$ & $20(12.3 \%)$ \\
\hline & cT3 & $134(82.2 \%)$ \\
\hline & cT4 & $7(4.3 \%)$ \\
\hline \multirow[t]{4}{*}{ Clinical N-stage, $\mathrm{n}(\%)^{\mathrm{a}}$} & $\mathrm{cNO}$ & $37(22.7 \%)$ \\
\hline & $\mathrm{cN} 1$ & $94(57.7 \%)$ \\
\hline & $\mathrm{cN} 2$ & $30(18.4 \%)$ \\
\hline & $\mathrm{cN} 3$ & $2(1.2 \%)$ \\
\hline \multirow{2}{*}{ Clinical M-stage, $\mathrm{n}(\%)^{\mathrm{a} *}$} & cM0 & $143(87.7 \%)$ \\
\hline & cM1 & $20(12.3 \%)$ \\
\hline \multirow[t]{6}{*}{ Clinical stage, $\mathrm{n}(\%)^{\mathrm{a}}$} & II & $41(25.2 \%)$ \\
\hline & III & $97(59.5 \%)$ \\
\hline & IVA & $5(3.1 \%)$ \\
\hline & IVB & $20(12.2 \%)$ \\
\hline & IVB & $20(12.2 \%)$ \\
\hline & Complete & $35(21.4 \%)$ \\
\hline \multirow[t]{3}{*}{ Clinical response (to NCRT), $\mathrm{n}(\%)^{\mathrm{b}}$} & Partial & $122(74.9 \%)$ \\
\hline & Stable disease & $5(3.1 \%)$ \\
\hline & Progressive disease & $1(0.6 \%)$ \\
\hline \multirow[t]{3}{*}{ Histology, n (\%) } & Well-differentiated & $18(11.0 \%)$ \\
\hline & Moderately differentiated & $74(45.4 \%)$ \\
\hline & Poorly differentiated & $71(43.6 \%)$ \\
\hline \multirow[t]{4}{*}{ Lymphatic invasion, n (\%) } & ly0 & $121(74.2 \%)$ \\
\hline & ly1 & $30(18.4 \%)$ \\
\hline & ly2 & $9(5.5 \%)$ \\
\hline & ly3 & $3(1.9 \%)$ \\
\hline \multirow[t]{3}{*}{ Venous invasion, $\mathrm{n}(\%)$} & v0 & $131(80.4 \%)$ \\
\hline & v1 & $29(17.8 \%)$ \\
\hline & v2 & $3(1.8 \%)$ \\
\hline \multirow[t]{5}{*}{ Pathological T-stage, n $(\%)^{\mathrm{c}}$} & pT0 & $60(36.8 \%)$ \\
\hline & pT1 & $16(9.8 \%)$ \\
\hline & pT2 & $30(18.4 \%)$ \\
\hline & pT3 & $55(33.8 \%)$ \\
\hline & pT4 & $2(1.2 \%)$ \\
\hline \multirow[t]{4}{*}{ Pathological N-stage, $\mathrm{n}(\%)^{\mathrm{c}}$} & pNO & $126(77.3 \%)$ \\
\hline & $\mathrm{pN} 1$ & $26(16.0 \%)$ \\
\hline & $\mathrm{pN} 2$ & $9(5.5 \%)$ \\
\hline & $\mathrm{pN} 3$ & $2(1.2 \%)$ \\
\hline \multirow[t]{2}{*}{ Pathological M-stage, $\mathrm{n}(\%)^{\mathrm{c}}$} & pM0 & $155(95.1 \%)$ \\
\hline & pM1 & $8(4.9 \%)$ \\
\hline \multirow[t]{2}{*}{ Pathological response, $\mathrm{n}(\%)^{\mathrm{c}}$} & Complete & $54(33.1 \%)$ \\
\hline & Partial & $109(66.9 \%)$ \\
\hline \multirow{8}{*}{ Postoperative complications, $\mathrm{n}(\%)^{\mathrm{d}}$} & None & $50(30.6 \%)$ \\
\hline & Grade I & $6(3.7 \%)$ \\
\hline & Grade II & $31(19.1 \%)$ \\
\hline & Grade IIIa & $50(30.7 \%)$ \\
\hline & Grade IIIb & $19(11.6 \%)$ \\
\hline & Grade IVa & $5(3.1 \%)$ \\
\hline & Grade IVb & 0 \\
\hline & Grade V & $2(1.2 \%)$ \\
\hline
\end{tabular}

CEA: Carcinoembryonic antigen; SCC: squamous cell carcinoma-related antigen; SD: standard deviation. apretherapeutic, according to TNM classification, eighth edition (11); baccording to Response Evaluation Criteria in Solid Tumours criteria (12); caccording to TNM classification, eighth edition (11); daccording to Clavien-Dindo classification of surgical complications (13). *Supraclavicular lymph node metastasis. 
index of recurrence and prognosis, and may provide important clues when considering indications for additional treatment in the future. The present study aimed to investigate the prognostic role of NLR values obtained at different treatment stages in patients with oesophageal squamous cell carcinoma.

\section{Patients and Methods}

Patients. This retrospective study enrolled 163 patients with oesophageal squamous cell carcinoma who underwent oesophagectomy with R0 resection after NCRT between April 2003 and August 2018 at Hiroshima University Hospital. Clinicopathological diagnosis of the tumours was performed based on the eighth edition of the TNM classification (11). Table I shows the clinicopathological features of the patients. Clinical tumour responses between pre-NCRT and restaging examinations before surgery were assessed according to the Response Evaluation Criteria in Solid Tumours criteria (12). Postoperative complications were assessed based on the Clavien-Dindo classification. Severe postoperative complications were defined as those classified as Clavien-Dindo grade IIIa or higher that developed within 30 days of surgery (13). This study was approved by the Institutional Review Board of Hiroshima University (approval number: E-2225). Informed consent was obtained from all patients for the data collected in the study.

Neoadjuvant chemoradiotherapy. NCRT comprised concurrent radiotherapy (40 Gy in 20 fractions) and chemotherapy with 5fluorouracil and docetaxel, cisplatin, or a combination of both (14-21). Patients with elevated serum creatinine level were treated with nedaplatin instead of cisplatin. The chemotherapy regimens were docetaxel/5-fluorouracil, cisplatin/5-fluorouracil, docetaxel/cisplatin/5fluorouracil, and nedaplatin/5-fluorouracil in 38 (23.2\%), 102 (62.6\%), $18(11.0 \%)$, and $5(3.2 \%)$ patients, respectively.

External beam radiotherapy with 10-MV X-rays was concurrently administered at 5 fractions per week for 4 weeks (total dose, $40 \mathrm{~Gy}$ ). A computed tomography simulator was used in the three-dimensional treatment planning. The irradiation field for upper thoracic tumours included the regions from the supraclavicular, cervical, and mediastinal lymph nodes to the carina. The mid-thoracic or lower thoracic tumours field included the cervical, mediastinal, and perigastric lymph nodes; the supraclavicular fossa was included when the cervical lymph nodes tested positive. The fields for oesophagogastric junction tumours included the mediastinal (lower than the subcarinal), perigastric, and celiac lymph nodes (18-20).

Surgical treatment. Surgery was scheduled 4-8 weeks after the completion of NCRT for all patients. All patients underwent open transthoracic $(n=128)$ or thoracoscopic oesophagectomy $(n=35)$ and lymph node dissection in at least two fields (thoracic and abdominal fields). EC in the upper and middle third of the thoracic oesophagus and lymph node metastasis in the superior mediastinum were treated using cervical lymphadenectomy. A gastric tube was subsequently lifted for cervical anastomosis with the oesophagus. The reconstruction path was the retrosternal $(n=104)$ or posterior mediastinal $(n=57)$ region or the region before the chest wall $(n=2)$. Three experts in oesophageal surgery performed these procedures.

Neutrophil-to-lymphocyte ratio. The NLR was calculated by dividing the absolute neutrophil count by the absolute lymphocyte count. The NLR was calculated at five points: Prior to chemoradiotherapy (pre CRT); presurgery; and 14 days (POD 14), 1 month (POM 1), and 2
Table II. Neutrophil, lymphocyte, and neutrophil-to-lymphocyte ratio (NLR) data for each treatment period in the study $(N=163)$.

\begin{tabular}{lcc}
\hline Time point & Parameter & Value \\
\hline Pre-CRT & Neutrophil count, $\mathrm{n} / \mu \mathrm{l}$ & $4,724.1 \pm 1,854.4$ \\
& Lymphocyte count, $\mathrm{n} / \mu \mathrm{l}$ & $1,710.7 \pm 607.5$ \\
NLR & $3.1 \pm 1.8$ \\
Pre-surgery & Neutrophil count, $\mathrm{n} / \mu \mathrm{l}$ & $2,863.9 \pm 1301.6$ \\
& Lymphocyte count, $\mathrm{n} / \mu \mathrm{l}$ & $999.8 \pm 447.9$ \\
POD 14 & NLR & $3.3 \pm 2.0$ \\
& Neutrophil count, $\mathrm{n} / \mu \mathrm{l}$ & $5,699.4 \pm 2,685.7$ \\
& Lymphocyte count, $\mathrm{n} / \mu \mathrm{l}$ & $714.4 \pm 327.2$ \\
POM 1 & NLR & $20.0 \pm 73.1$ \\
& Neutrophil count, $\mathrm{n} / \mu \mathrm{l}$ & $4,284.1 \pm 1,951.4$ \\
& Lymphocyte count, $\mathrm{n} / \mu \mathrm{l}$ & $883.7 \pm 427.3$ \\
POM 2 & NLR & $6.1 \pm 5.2$ \\
& Neutrophil count, $\mathrm{n} / \mu \mathrm{l}$ & $3,538.1 \pm 2,290.6$ \\
& Lymphocyte count, $\mathrm{n} / \mu \mathrm{l}$ & $930.2 \pm 454.8$ \\
& NLR & $28.5 \pm 208.5$ \\
\hline
\end{tabular}

Values are shown as the mean \pm standard deviation. CRT: Chemoradiotherapy; POD: postoperative day; POM: postoperative month.

months (POM 2) postoperatively. To evaluate the change in NLR due to CRT and surgery, the following parameters were also evaluated:

i) $\triangle$ NLR $($ CRT $)=($ NLR presurgery - pre-CRT NLR $)$

ii) $\triangle$ NLR (POD 14) $=($ NLR 14 days after surgery - NLR presurgery)

iii) $\triangle$ NLR $($ POM 1$)=($ NLR 1 month after surgery -

NLR presurgery)

iv) $\triangle$ NLR (POM 2)=(NLR 2 months after surgery -

NLR presurgery)

Statistical analyses. The results are presented as percentage or medians unless stated otherwise. Survival was analysed using Kaplan-Meier curves and compared using log-rank tests. Relapsefree survival (RFS) was defined as the interval between the date of surgery until the first event (recurrence or death from any cause) or the most recent follow-up. Overall survival (OS) was defined as the time from the date of surgery until death due to any cause or the last follow-up visit. Optimal cut-off values for NLR were determined from receiver operating characteristic curves. Multivariate Cox regression analysis was performed to identify the independent predictors of OS and RFS. A backward stepwise method was used to select variables for the multivariate analysis. Statistical analysis was performed using JMP Pro 15 software (2019; SAS Institute, Cary, NC, USA), with a significance level of $p<0.05$.

\section{Results}

NLR data for each treatment period. The NLR values (mean \pm standard deviation) were $3.1 \pm 1.8$ pre CRT, $3.3 \pm 2.0$ pre surgery, 20.0 \pm 73.1 at POD $14,6.1 \pm 5.2$ at POM 1, and $28.5 \pm 208.5$ at POM 2 (Table II).

Optimal cut-off of the NLR at each treatment period for predicting the 3-year OS rate. The optimal cut-off values of NLR to predict good OS pre-CRT, pre-surgery, and at POD 
Table III. Results of the univariate and multivariate analyses of prognostic factors for recurrence-free survival.

\begin{tabular}{|c|c|c|c|c|c|c|c|}
\hline \multirow[b]{2}{*}{ Variable } & & \multicolumn{3}{|c|}{ Univariate analysis } & \multicolumn{3}{|c|}{ Multivariate analysis } \\
\hline & & HR & $95 \% \mathrm{CI}$ & $p$-Value & HR & $95 \% \mathrm{CI}$ & $p$-Value \\
\hline Age, years & Continuous & 1.01 & $0.97-1.02$ & 0.8666 & - & & - \\
\hline \multirow[t]{2}{*}{ Gender } & Female (reference) & 1 & & & 1 & & \\
\hline & Male & 2.13 & $1.07-4.24$ & 0.0309 & 1.65 & $0.78-3.47$ & 0.6868 \\
\hline \multirow{2}{*}{ Performance status } & 0 (reference) & 1 & & & - & - & - \\
\hline & 1 & 1.37 & $0.76-2.47$ & 0.3035 & - & - & - \\
\hline $\mathrm{SCC}$ & Continuous & 0.99 & $0.90-1.08$ & 0.9614 & - & - & - \\
\hline CEA & Continuous & 1.08 & $0.98-1.17$ & 0.0936 & - & - & - \\
\hline \multirow[t]{2}{*}{ Primary tumour location } & Middle, lower (reference) & 1 & & & - & - & - \\
\hline & Upper & 1.02 & $0.61-1.69$ & 0.9292 & - & - & - \\
\hline \multirow[t]{2}{*}{ Clinical T-stage ${ }^{a}$} & 1,2 (reference) & 1 & & & - & - & - \\
\hline & 3,4 & 1.62 & $0.84-3.13$ & 0.1465 & - & - & - \\
\hline \multirow[t]{2}{*}{ Clinical N-stage ${ }^{a}$} & 0 (reference) & 1 & & & - & - & - \\
\hline & $1,2,3$ & 1.41 & $0.86-2.32$ & 0.1673 & - & - & - \\
\hline \multirow[t]{2}{*}{ Clinical M-stage ${ }^{a}$} & 0 (reference) & 1 & & & - & - & - \\
\hline & 1 & 1.60 & $0.90-2.83$ & 0.1043 & - & - & - \\
\hline \multirow[t]{2}{*}{ Clinical response ${ }^{b}$} & CR, PR (reference) & 1 & & & 1 & & \\
\hline & $\mathrm{SD}, \mathrm{PD}$ & 3.80 & $1.64-8.81$ & 0.0087 & 2.81 & $1.15-6.87$ & 0.0233 \\
\hline \multirow[t]{2}{*}{ NLR } & $<4.5$ (reference) & 1 & & & 1 & & \\
\hline & $\geq 4.5$ & 5.51 & $3.45-8.81$ & $<0.0001$ & 4.44 & $2.69-7.34$ & $<0.0001$ \\
\hline \multirow[t]{2}{*}{ Pathological T-stage ${ }^{c}$} & $0,1,2$ (reference) & 1 & & & 1 & & \\
\hline & 3,4 & 1.84 & $1.22-2.78$ & 0.0350 & 1.51 & $0.97-2.35$ & 0.1898 \\
\hline \multirow[t]{2}{*}{ Pathological N-stage ${ }^{c}$} & 0 (reference) & 1 & & & 1 & & \\
\hline & $1,2,3$ & 2.64 & $1.74-4.00$ & $<0.0001$ & 1.67 & $1.07-2.61$ & 0.0003 \\
\hline \multirow[t]{2}{*}{ Pathological M-stage ${ }^{c}$} & 0 (reference) & 1 & & & - & - & - \\
\hline & 1 & 2.28 & $0.99-5.24$ & 0.0514 & - & - & - \\
\hline \multirow[t]{2}{*}{ Histology } & Other (reference) & 1 & & & - & - & - \\
\hline & Poorly differentiated & 1.38 & $0.92-2.08$ & 0.1171 & - & - & - \\
\hline \multirow[t]{2}{*}{ Lymphatic invasion } & 0 (reference) & 1 & & & 1 & & \\
\hline & $1,2,3$ & 2.79 & $1.83-4.26$ & $<0.0001$ & 1.90 & $1.05-3.44$ & 0.0395 \\
\hline \multirow[t]{2}{*}{ Venous invasion } & 0 (reference) & 1 & & & 1 & & \\
\hline & 1,2 & 2.28 & $1.45-3.59$ & 0.0004 & 1.20 & $0.64-2.26$ & 0.7783 \\
\hline \multirow[t]{2}{*}{ Postoperative complications ${ }^{\mathrm{d}}$} & Grade II or lower (reference) & 1 & & & - & - & - \\
\hline & Grade III or higher & 1.15 & $0.77-1.73$ & 0.4787 & - & - & - \\
\hline
\end{tabular}

CEA: Carcinoembryonic antigen; CI: confidence interval; CR: complete response; HR: hazard ratio; NLR: neutrophil-to-lymphocyte ratio; PD: progressive disease; PR: partial response; RFS: relapse-free survival; SCC: squamous cell carcinoma-related antigen; SD: stable disease. aPretherapeutic, according to TNM classification, eighth edition (11); baccording to Response Evaluation Criteria in Solid Tumours criteria (12);

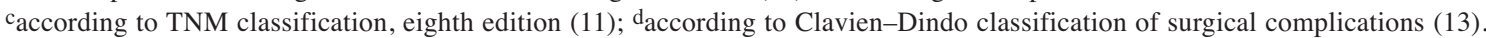

14, POM 1, and POM 2 were 8.1 [area under the curve $=0.4822,95 \%$ confidence interval $(\mathrm{CI})=0.39-0.57$, $p=0.7861], 2.1$ (AUC $=0.6084,95 \% \mathrm{CI}=0.51-0.69, p=0.0196)$, $11.2 \quad(\mathrm{AUC}=0.5657,95 \% \quad \mathrm{CI}=0.47-0.65, p=0.0075), 4.5$ (AUC $=0.7878,95 \% \mathrm{CI}=0.70-0.85, p<0.0001)$, and 3.3 (AUC $=0.6041,95 \% \mathrm{CI}=0.51-0.68, p=0.0069)$, respectively.

For $\triangle$ NLR CRT, $\triangle$ NLR POD 14, $\triangle$ NLR POM 1, and $\triangle$ NLR POM 2, the optimal cut-off values of NLR to predict OS were 0.6 (AUC $=0.5616,95 \% \mathrm{CI}=0.46-0.65, p=0.1006)$, $10.0 \quad(\mathrm{AUC}=0.5287,95 \% \quad \mathrm{CI}=0.43-0.62, p=0.0146), 2.0$ (AUC $=0.6898,95 \% \mathrm{CI}=0.59-0.76, p=0.0003)$, and 1.4 (AUC $=0.5294,95 \% \mathrm{CI}=0.43-0.61, p=0.0188)$, respectively.

The NLR of POM 1, which had the highest AUC, was adopted as a prognostic factor.
Univariate and multivariate analyses for RFS. Univariate analysis showed that male sex [hazard ratio $(H R)=2.13$, 95\% CI=1.07-4.24], a poor clinical response (stable or progressive disease $)(\mathrm{HR}=3.80,95 \% \mathrm{CI}=1.64-8.81)$, NLR $\geq 4.5(\mathrm{HR}=5.51,95 \% \mathrm{CI}=3.45-8.81)$, pathological T-stage 3 or $4(\mathrm{HR}=1.84,95 \% \mathrm{CI}=1.22-2.78), \mathrm{N}$-stage $1-3(\mathrm{HR}=2.64$, $95 \% \mathrm{CI}=1.74-4.00)$, lymphatic invasion $(\mathrm{HR}=2.79,95 \%$ $\mathrm{CI}=1.83-4.26)$ and venous invasion ( $\mathrm{HR}=2.28,95 \%$ $\mathrm{CI}=1.45-3.59)$ were significantly associated with reduced RFS (Table III).

Multivariate analysis showed that a poor clinical response $(\mathrm{HR}=3.80,95 \% \mathrm{CI}=0.13-0.37), \mathrm{NLR} \geq 4.5$ (HR=0.22, 95\% $\mathrm{CI}=0.13-0.37)$, pathological nodal metastasis $(\mathrm{HR}=1.67,95 \%$ $\mathrm{CI}=1.07-2.61)$, and lymphatic invasion $(\mathrm{HR}=1.90,95 \%$ 
Table IV. Results of the univariate and multivariate analyses of the prognostic factors for overall survival.

\begin{tabular}{|c|c|c|c|c|c|c|c|}
\hline \multirow[b]{2}{*}{ Variable } & & \multicolumn{3}{|c|}{ Univariate analysis } & \multicolumn{3}{|c|}{ Multivariate analysis } \\
\hline & & HR & $95 \% \mathrm{CI}$ & $p$-Value & HR & $95 \% \mathrm{CI}$ & $p$-Value \\
\hline Age, years & Continuous & 0.99 & $0.97-1.02$ & 0.8642 & & & \\
\hline \multirow[t]{2}{*}{ Gender } & Female (reference) & 1 & & & 1 & & \\
\hline & Male & 2.24 & $1.12-4.45$ & 0.0100 & 1.76 & $0.84-3.71$ & 0.7759 \\
\hline \multirow[t]{2}{*}{ Performance status } & 0 (reference) & 1 & & & & & \\
\hline & 1 & 1.54 & $0.87-2.72$ & 0.1333 & & & \\
\hline SCC & Continuous & 0.99 & $0.90-1.08$ & 0.9982 & & & \\
\hline CEA & Continuous & 1.07 & $0.97-1.16$ & 0.1566 & & & \\
\hline \multirow[t]{2}{*}{ Primary tumour location } & Middle, lower (reference) & 1 & & & & & \\
\hline & Upper & 1.06 & $0.65-1.74$ & 0.7955 & & & \\
\hline \multirow[t]{2}{*}{ Clinical T-stage ${ }^{a}$} & 1,2 (reference) & 1 & & & & & \\
\hline & 3,4 & 1.44 & $0.77-2.71$ & 0.2464 & & & \\
\hline \multirow[t]{2}{*}{ Clinical N-stage ${ }^{a}$} & 0 (reference) & 1 & & & & & \\
\hline & $1,2,3$ & 1.46 & $0.89-2.39$ & 0.1303 & & & \\
\hline \multirow[t]{2}{*}{ Clinical M-stage ${ }^{a}$} & 0 (reference) & 1 & & & & & \\
\hline & 1 & 1.34 & $0.75-2.36$ & 0.3113 & & & \\
\hline \multirow{2}{*}{ Clinical response ${ }^{\mathrm{b}}$} & CR, PR (reference) & 1 & & & 1 & & \\
\hline & $\mathrm{SD}, \mathrm{PD}$ & 4.89 & $2.10-11.36$ & 0.0002 & 3.83 & $1.54-9.49$ & 0.0037 \\
\hline \multirow[t]{2}{*}{ NLR } & $<4.5$ (reference) & 1 & & & 1 & & \\
\hline & $\geq 4.5$ & 5.11 & $3.23-8.10$ & $<0.0001$ & 3.88 & $2.38-6.32$ & $<0.0001$ \\
\hline \multirow[t]{2}{*}{ Pathological T-stage } & $0,1,2$ (reference) & 1 & & & 1 & & \\
\hline & 3,4 & 2.02 & $1.35-3.03$ & 0.0006 & 1.44 & $1.23-2.57$ & 0.0247 \\
\hline \multirow{2}{*}{ Pathological N-stage } & 0 (reference) & 1 & & & 1 & & \\
\hline & $1,2,3$ & 2.49 & $1.66-3.75$ & $<0.0001$ & 1.44 & $1.10-2.30$ & 0.0008 \\
\hline \multirow{2}{*}{ Pathological M-stage ${ }^{c}$} & 0 (reference) & 1 & & & & & \\
\hline & 1 & 1.99 & $0.86-4.56$ & 0.1032 & & & \\
\hline \multirow[t]{2}{*}{ Histology } & Other (reference) & 1 & & & & & \\
\hline & Poorly differentiated & 1.19 & $0.80-1.78$ & 0.3759 & & & \\
\hline \multirow[t]{2}{*}{ Lymphatic invasion } & 0 (reference) & 1 & & & 1 & & \\
\hline & $1,2,3$ & 2.59 & $1.71-3.91$ & $<0.0001$ & 1.48 & $0.80-2.75$ & 0.3805 \\
\hline \multirow[t]{2}{*}{ Venous invasion } & 0 (reference) & 1 & & & 1 & & \\
\hline & 1,2 & 2.36 & $1.52-3.67$ & 0.0001 & 1.47 & $0.77-2.80$ & 0.8621 \\
\hline \multirow{2}{*}{ Postoperative complications ${ }^{\mathrm{d}}$} & Grade II or lower (reference) & 1 & & & & & \\
\hline & Grade III or higher & 1.08 & $0.72-1.61$ & 0.6946 & & & \\
\hline
\end{tabular}

CEA: Carcinoembryonic antigen; CI: confidence interval; CR: complete response; HR: hazard ratio; NLR: neutrophil-to-lymphocyte ratio; PD: progressive disease; PR: partial response; RFS: relapse-free survival; SCC: squamous cell carcinoma-related antigen; SD: stable disease. aPretherapeutic, according to TNM classification, eighth edition (11); baccording to Response Evaluation Criteria in Solid Tumours criteria (12); ${ }^{c}$ according to TNM classification, eighth edition (11); ${ }^{d}$ according to Clavien-Dindo classification of surgical complications (13).

$\mathrm{CI}=1.05-3.44)$ remained significantly associated with poor RFS (Table III).

Univariate and multivariate analyses for OS. Univariate analysis showed that male sex $(\mathrm{HR}=2.24,95 \% \mathrm{CI}=1.12-4.45)$, a poor clinical response $(\mathrm{HR}=4.89,95 \% \mathrm{CI}=2.10-11.36), \mathrm{NLR} \geq 4.5$ $(\mathrm{HR}=5.11$, 95\% CI=3.23-8.10), high pathological T-stage $(\mathrm{HR}=2.02,95 \% \mathrm{CI}=1.35-3.03)$, lymph node metastasis $(\mathrm{HR}=2.49$, $95 \% \mathrm{CI}=1.66-3.75)$, lymphatic invasion $(\mathrm{HR}=2.59,95 \% \mathrm{CI}=1.71-$ $3.91)$ and venous invasion $(\mathrm{HR}=2.36,95 \% \mathrm{CI}=1.52-3.67)$ were significantly associated with poor OS (Table IV).

Multivariate analysis showed that a poor clinical response $(\mathrm{HR}=3.83,95 \% \mathrm{CI}=1.54-9.49), \mathrm{NLR} \geq 4.5(\mathrm{HR}=3.88,95 \%$ $\mathrm{CI}=2.38-6.32)$, high pathological T-stage $(\mathrm{HR}=1.44,95 \%$
$\mathrm{CI}=1.23-2.57)$ and lymph node metastasis ( $\mathrm{HR}=1.44,95 \%$ $\mathrm{CI}=1.10-2.30)$ were significantly associated with poor OS (Table IV).

RFS and OS after NCRT. Five-year RFS (Figure 1A) and OS (Figure 1B) rates were higher in patients with low NLRs at POM $1(<4.5)$ than in those with high values $(\geq 4.5)(81.1 \%$ vs. $22.9 \%$ and $80.9 \%$ vs. $23.3 \%$, respectively, both $p<0.0001)$.

RFS and OS according to pathological response and postoperative complications. Whether patients attained pathological complete response (pCR) or not, the 5-year RFS rates $(93.5 \%$ vs. $45.5 \%$ and $69.4 \%$ vs. $14.6 \%$, respectively, $p<0.0001)$ and OS rates $(90.4 \% v s .47 .6 \%$ and $71.3 \% v s$. 

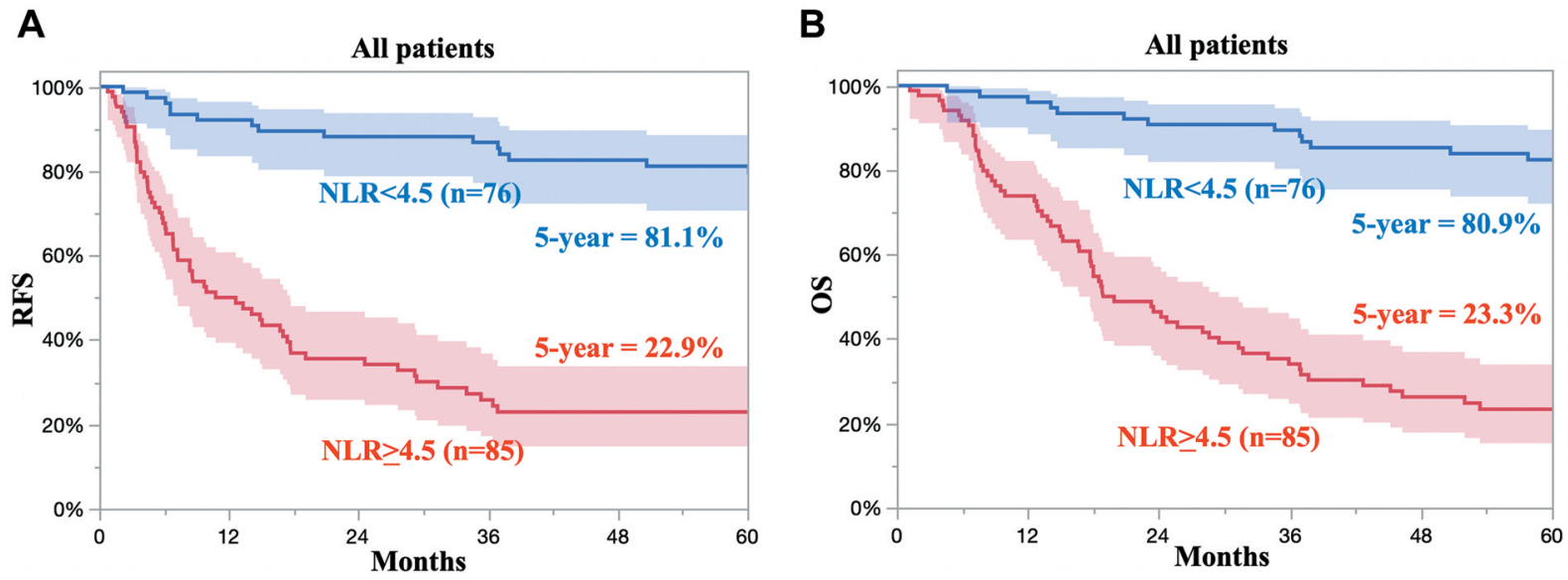

Figure 1. Relapse-free survival (RFS) (A) and overall survival (OS) (B) after neoadjuvant chemoradiotherapy in all patients, based on the neutrophilto-lymphocyte ratio $(N L R)$.

$13.1 \%$, respectively, $p<0.0001)$ were higher in patients with a low NLR $(<4.5)$ at POM 1 than in those with high values (Figure 2A and B).

Whether patients had no or only mild postoperative complications or severe ones, the 5-year RFS rates $(79.7 \% \mathrm{vs}$. $24.7 \%$ and $79.6 \%$ vs. $22.0 \%$, respectively, $p<0.0001)$ and OS rates $(82.3 \%$ vs. $23.7 \%$ and $79.4 \%$ vs. $23.5 \%$, respectively, $p<0.0001)$ were higher with a low NLR $(<4.5)$ at POM 1 than in those with high values (Figure 2C and D).

\section{Discussion}

Lymphocytes play a role in tumour suppression and immunity and are widely used as indicators of immunocompetence (22, 23). The production of neutrophils, however, increases in response to inflammation. Neutrophils induce the production of chemokines and cytokines that enhance tumour growth, invasion, and angiogenesis; therefore, they are closely associated with inflammation and tumour progression (24). The NLR is an indicator that predicts the posthospitalization course of critically ill patients admitted to intensive care units (25); however, it has recently been reported as an oncological prognostic marker. NLR is one of the most popular methods for assessing the nutritional status of cellular components, and there is a large body of rigorous evidence supporting this methodology. It does not involve any additional costs to measure compared with other biomarkers (5-9).

The NLR is often reported as a risk factor for prognosis and recurrence (5-10), but it is useful in predicting preoperative treatment effects (26) and postoperative complications (27). The NLR is also associated with the prediction of preoperative treatment efficacy in EC. There have been various reports on the timing of NLR measurements (before and after the start of preoperative treatment) and on the amount of change in the
NLR with treatment $(5-9,26,28,29)$. However, data on postoperative NLR in EC are still insufficient compared with other cancer types $(30,31)$.

In this study, we investigated the correlation between perioperative NLR, recurrence, and prognosis in advanced resectable oesophageal squamous cell carcinoma. We hypothesized that changes in the immune status in cancer over time and the postoperative status may contribute to early recurrence, which suggests they are important as prognostic factors. Therefore, we decided to evaluate the immune status in patients with cancer before treatment and after preoperative CRT and surgery. Three time points (POD 14, POM 1, and POM 2) were adopted for measurement.

We also focused on treatment-related changes in immune status because dynamic changes in the NLR before and after surgery have been reported (10). Nonetheless inflammation (preoperative stricture, oesophagitis, and pneumonia) and postoperative surgical invasion and complications may contribute to the NLR in EC. We also hypothesized that the postoperative NLR suggests the patient's postoperative immune status, which is more important as a prognostic factor than the change in NLR value. Thus, we examined the prognostic value of the NLR and its changes at each treatment point. The NLR at POM 1 exhibited the strongest correlation with prognosis and was identified as an important prognostic factor.

In the subgroup analysis, $\mathrm{pCR}$ and non-pCR cases were compared. Although the prognosis of non-pCR cases is worse than that of pCR cases $(8,32)$, more than half of the non-pCR cases with a high NLR had recurrence within 1 year of surgery, which indicates a very poor prognosis. Even in patients with $\mathrm{pCR}$, half with a high NLR had recurrence within 3 years, indicating a poor prognosis. These results suggest that patients with a high NLR should be considered for additional adjuvant therapy, even if pCR is attained; strict follow-up may be necessary. 
A

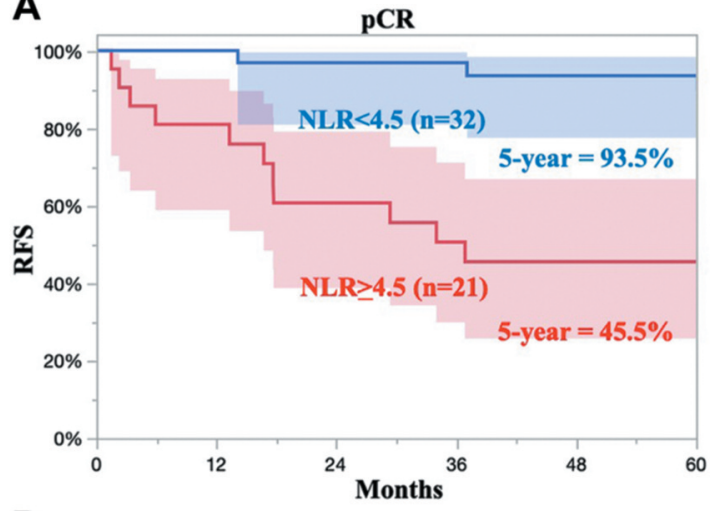

B

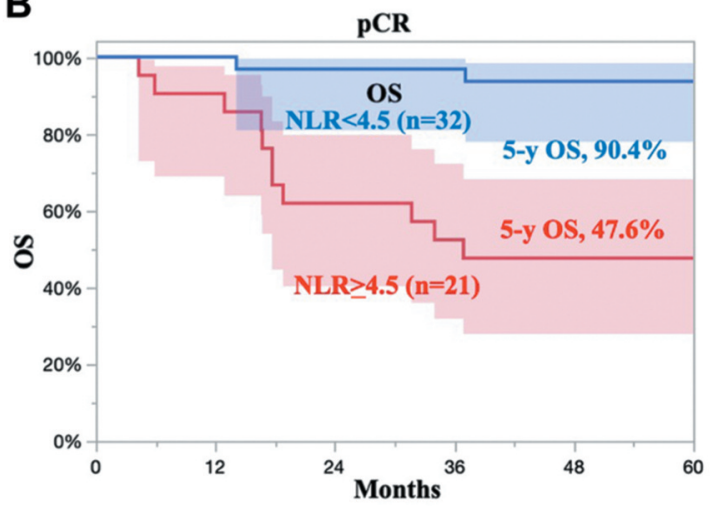

C

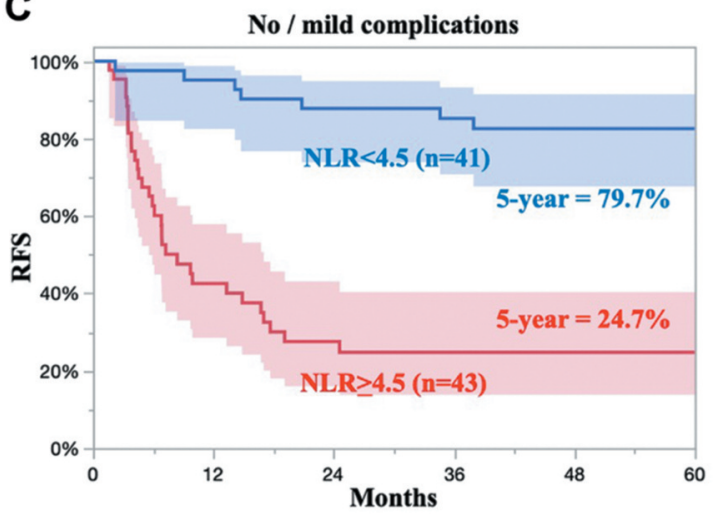

D

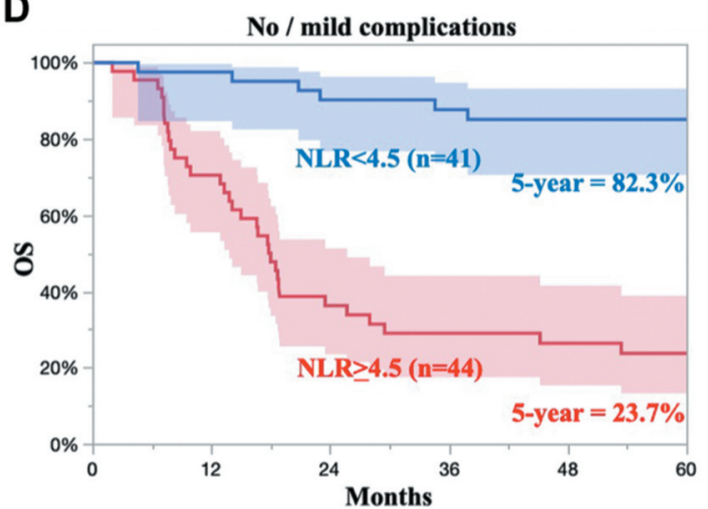

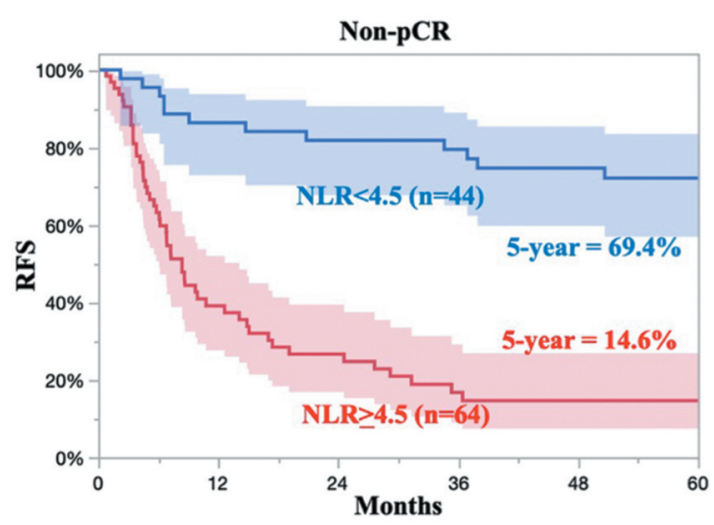
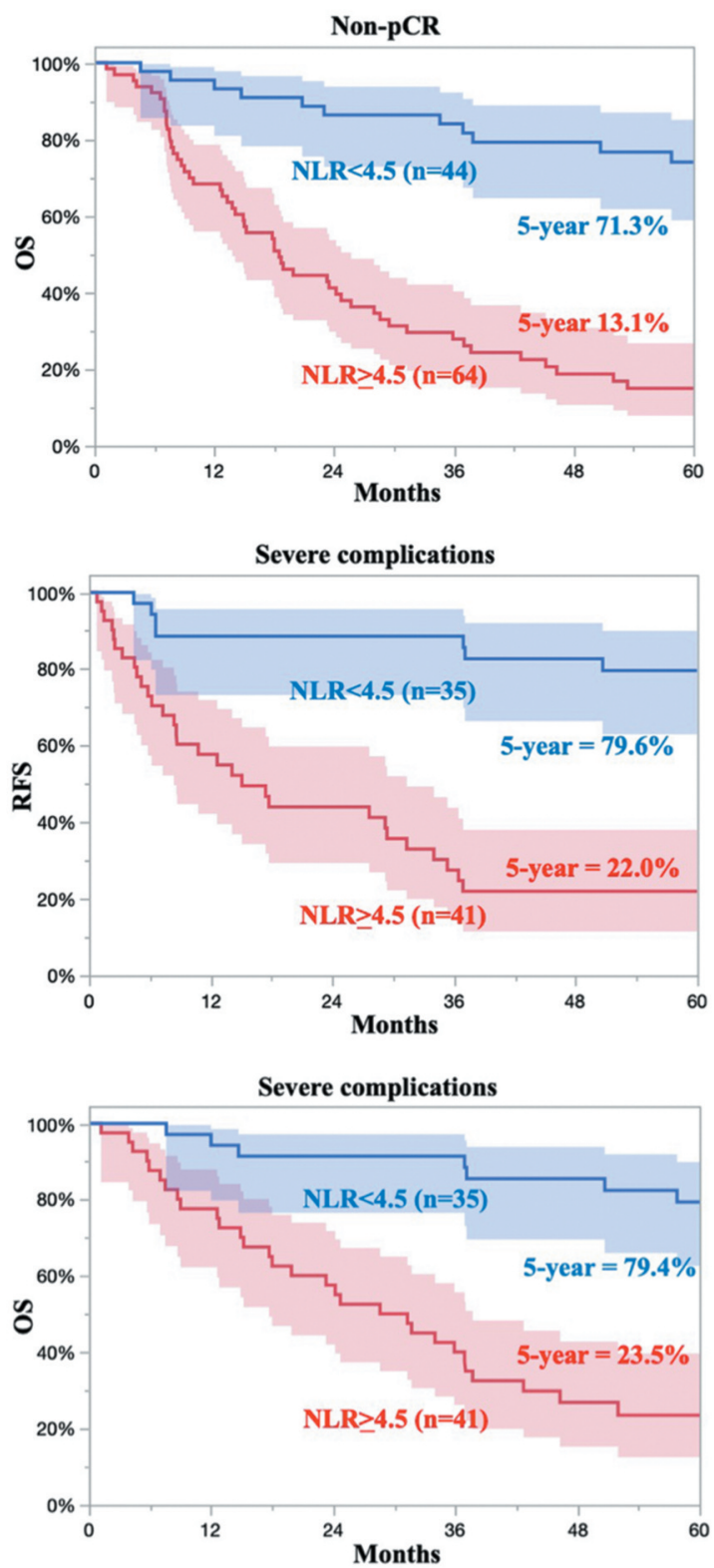

Figure 2. Relapse-free (RFS) and overall (OS) survival after neoadjuvant chemoradiotherapy (NCRT) in patients according to the pathological response ( $A$ and $B$ and postoperative complications (C and D), based on the neutrophil-to-lymphocyte ratio (NLR). pCR: Pathological complete response. 
Postoperative complications have been reported as a factor for poor prognosis $(33,34)$, and the occurrence of severe ones is likely to affect blood sampling data, including neutrophil and lymphocyte counts, after surgery. Therefore, we performed another analysis for groups with and without severe postoperative complications (Clavien-Dindo grade III or higher). Regardless of the presence of severe complications, patients with a high NLR still had a very high recurrence rate at a relatively early stage and a poor prognosis. Conversely, patients with a low NLR had a relatively good prognosis, even if they developed severe complications.

Currently, immune checkpoint inhibitors have been approved in the field of EC, and multidisciplinary treatment for EC is expected to develop further in the future (4). This study is significant as the detection of cases at high risk for postoperative recurrence and poor prognosis is useful in determining indications for additional adjuvant therapy.

This study was limited by a retrospective study design, a small number of patients, and the use of data from a single institution.

In summary, we showed that the NLR at 1 month after surgery correlated with prognosis and was also a useful predictor of recurrence. As a high-risk group, patients with a high NLR require rigorous follow-up, and postoperative adjuvant therapy should be considered for them.

\section{Conflicts of Interest}

The Authors have no related conflicts of interest to declare.

\section{Authors' Contributions}

MOh and YH drafted the article. MOh, YH, ME, YI, TK, TY, RH, and $\mathrm{NK}$ contributed to patient care. MOh, MK, JH, and $\mathrm{MH}$ performed the literature search. MOh, YH, ME, YI, TK, TY, RH, $\mathrm{NK}$, and MOk participated in the critical revision of the article. All Authors read and approved the final article.

\section{References}

1 Sjoquist KM, Burmeister BH, Smithers BM, Zalcberg JR, Simes RJ, Barbour A, Gebski V and Australasian Gastro-Intestinal Trials Group: Survival after neoadjuvant chemotherapy or chemoradiotherapy for resectable oesophageal carcinoma: an updated meta-analysis. Lancet Oncol 12(7): 681-692, 2011. PMID: 21684205. DOI: 10.1016/S1470-2045(11)70142-5

2 van Hagen P, Hulshof MC, van Lanschot JJ, Steyerberg EW, van Berge Henegouwen MI, Wijnhoven BP, Richel DJ, Nieuwenhuijzen GA, Hospers GA, Bonenkamp JJ, Cuesta MA, Blaisse RJ, Busch OR, ten Kate FJ, Creemers GJ, Punt CJ, Plukker JT, Verheul HM, Spillenaar Bilgen EJ, van Dekken H, van der Sangen MJ, Rozema T, Biermann K, Beukema JC, Piet AH, van Rij CM, Reinders JG, Tilanus HW, van der Gaast A and CROSS Group: Preoperative chemoradiotherapy for esophageal or junctional cancer. N Engl J Med 366(22): 2074-2084, 2012. PMID: 22646630. DOI: 10.1056/NEJMoa1112088
3 Tepper J, Krasna MJ, Niedzwiecki D, Hollis D, Reed CE, Goldberg R, Kiel K, Willett C, Sugarbaker D and Mayer R: Phase III trial of trimodality therapy with cisplatin, fluorouracil, radiotherapy, and surgery compared with surgery alone for esophageal cancer: CALGB 9781. J Clin Oncol 26(7): 10861092, 2008. PMID: 18309943. DOI: 10.1200/JCO.2007.12.9593

4 Kelly RJ, Ajani JA, Kuzdzal J, Zander T, Van Cutsem E, Piessen G, Mendez G, Feliciano J, Motoyama S, Lièvre A, Uronis H, Elimova E, Grootscholten C, Geboes K, Zafar S, Snow S, Ko AH, Feeney K, Schenker M, Kocon P, Zhang J, Zhu L, Lei M, Singh P, Kondo K, Cleary JM, Moehler M and CheckMate 577 Investigators: Adjuvant nivolumab in resected esophageal or gastroesophageal junction cancer. N Engl J Med 384(13): 11911203, 2021. PMID: 33789008. DOI: 10.1056/NEJMoa2032125

5 Paramanathan A, Saxena A and Morris DL: A systematic review and meta-analysis on the impact of pre-operative neutrophil lymphocyte ratio on long term outcomes after curative intent resection of solid tumours. Surg Oncol 23(1): 31-39, 2014. PMID: 24378193. DOI: 10.1016/j.suronc.2013.12.001

6 Templeton AJ, McNamara MG, Šeruga B, Vera-Badillo FE, Aneja P, Ocaña A, Leibowitz-Amit R, Sonpavde G, Knox JJ, Tran B, Tannock IF and Amir E: Prognostic role of neutrophilto-lymphocyte ratio in solid tumors: a systematic review and meta-analysis. J Natl Cancer Inst 106(6): dju124, 2014. PMID: 24875653. DOI: $10.1093 /$ jnci/dju 124

7 Guthrie GJ, Charles KA, Roxburgh CS, Horgan PG, McMillan DC and Clarke SJ: The systemic inflammation-based neutrophillymphocyte ratio: experience in patients with cancer. Crit Rev Oncol Hematol 88(1): 218-230, 2013. PMID: 23602134. DOI: 10.1016/j.critrevonc.2013.03.010

8 Zhou XL, Li YQ, Zhu WG, Yu CH, Song YQ, Wang WW, He DC, Tao GZ and Tong YS: Neutrophil-to-lymphocyte ratio as a prognostic biomarker for patients with locally advanced esophageal squamous cell carcinoma treated with definitive chemoradiotherapy. Sci Rep 7: 42581, 2017. PMID: 28195186. DOI: $10.1038 /$ srep42581

9 Sharaiha RZ, Halazun KJ, Mirza F, Port JL, Lee PC, Neugut AI, Altorki NK and Abrams JA: Elevated preoperative neutrophil:lymphocyte ratio as a predictor of postoperative disease recurrence in esophageal cancer. Ann Surg Oncol 18(12): 33623369, 2011. PMID: 21547702. DOI: 10.1245/s 10434-011-1754-8

10 Al Lawati Y, Cools-Lartigue J, Ramirez-GarciaLuna JL, MolinaFranjola JC, Pham D, Skothos E, Mueller C, Spicer J and Ferri L: Dynamic alteration of neutrophil-to-lymphocyte ratio over treatment trajectory is associated with survival in esophageal adenocarcinoma. Ann Surg Oncol 27(11): 4413-4419, 2020. PMID: 32363513. DOI: 10.1245/s10434-020-08521-7

11 Brierley JD, Gospodarowicz MK and Wittekind C: TNM Classification of Malignant Tumours. Eighth Edition. Chichester, Wiley-Blackwell, 2016.

12 Therasse P, Arbuck SG, Eisenhauer EA, Wanders J, Kaplan RS, Rubinstein L, Verweij J, Van Glabbeke M, van Oosterom AT, Christian MC and Gwyther SG: New guidelines to evaluate the response to treatment in solid tumors. European Organization for Research and Treatment of Cancer, National Cancer Institute of the United States, National Cancer Institute of Canada. J Natl Cancer Inst 92(3): 205-216, 2000. PMID: 10655437. DOI: 10.1093/jnci/92.3.205

13 Katayama H, Kurokawa Y, Nakamura K, Ito H, Kanemitsu Y, Masuda N, Tsubosa Y, Satoh T, Yokomizo A, Fukuda H and 
Sasako M: Extended Clavien-Dindo classification of surgical complications: Japan Clinical Oncology Group postoperative complications criteria. Surg Today 46(6): 668-685, 2016. PMID: 26289837. DOI: 10.1007/s00595-015-1236-x

14 Hamai Y, Hihara J, Emi M, Furukawa T, Murakami Y, Nishibuchi I, Ibuki Y, Yamakita I, Kurokawa T, Nagata Y and Okada M: Evaluation of prognostic factors for esophageal squamous cell carcinoma treated with neoadjuvant chemoradiotherapy followed by surgery. World J Surg 42(5): 1496-1505, 2018. PMID: 29030675. DOI: 10.1007/s00268-017-4283-1

15 Hamai Y, Emi M, Ibuki Y, Murakami Y, Nishibuchi I, Nagata Y, Furukawa T, Kurokawa T, Ohsawa M and Okada M: Early recurrence and cancer death after trimodal therapy for esophageal squamous cell carcinoma. Anticancer Res 39(3): 1433-1440, 2019. PMID: 30842179. DOI: 10.21873/anticanres.13259

16 Hamai Y, Hihara J, Emi M, Furukawa T, Ibuki Y, Yamakita I, Kurokawa $\mathrm{T}$ and Okada $\mathrm{M}$ : Effects of neoadjuvant chemoradiotherapy on pathological TNM stage and their prognostic significance for surgically-treated esophageal squamous cell carcinoma. Anticancer Res 37(10): 5639-5646, 2017. PMID: 28982881. DOI: 10.21873/anticanres.11999

17 Hamai Y, Hihara J, Emi M, Furukawa T, Yamakita I, Kurokawa $\mathrm{T}$ and Okada M: Ability of Fluorine-18 fluorodeoxyglucose positron emission tomography to predict outcomes of neoadjuvant chemoradiotherapy followed by surgical treatment for esophageal squamous cell carcinoma. Ann Thorac Surg 102(4): 1132-1139, 2016. PMID: 27319990. DOI: 10.1016/j.athoracsur.2016.04.011

18 Emi M, Hihara J, Hamai Y, Aoki Y, Okada M, Kenjo M and Murakami Y: Neoadjuvant chemoradiotherapy with docetaxel, cisplatin, and 5-fluorouracil for esophageal cancer. Cancer Chemother Pharmacol 69(6): 1499-1505, 2012. PMID: 22382882. DOI: $10.1007 / \mathrm{s} 00280-012-1853-7$

19 Hamai Y, Hihara J, Emi M, Murakami Y, Kenjo M, Nagata Y and Okada M: Results of neoadjuvant chemoradiotherapy with docetaxel and 5-fluorouracil followed by esophagectomy to treat locally advanced esophageal cancer. Ann Thorac Surg 99(6): 18871893, 2015. PMID: 25912745. DOI: 10.1016/j.athoracsur. 2015.02.042

20 Murakami Y, Hamai Y, Emi M, Hihara J, Imano N, Takeuchi Y, Takahashi I, Nishibuchi I, Kimura T, Okada M and Nagata Y: Longterm results of neoadjuvant chemoradiotherapy using cisplatin and 5-fluorouracil followed by esophagectomy for resectable, locally advanced esophageal squamous cell carcinoma. J Radiat Res 59(5): 616-624, 2018. PMID: 29939306. DOI: 10.1093/jrr/rry047

21 Hamai Y, Emi M, Ibuki Y, Murakami Y, Nishibuchi I, Nagata Y, Furukawa T, Kurokawa T, Ohsawa M, Yoshikawa T and Okada $\mathrm{M}$ : Predictions of pathological features and recurrence based on FDG-PET findings of esophageal squamous cell carcinoma after trimodal therapy. Ann Surg Oncol 27(11): 4422-4430, 2020. PMID: 32405978. DOI: 10.1245/s10434-020-08609-0

22 Noble F, Mellows T, McCormick Matthews LH, Bateman AC, Harris S, Underwood TJ, Byrne JP, Bailey IS, Sharland DM, Kelly JJ, Primrose JN, Sahota SS, Bateman AR, Thomas GJ and Ottensmeier $\mathrm{CH}$ : Tumour infiltrating lymphocytes correlate with improved survival in patients with oesophageal adenocarcinoma. Cancer Immunol Immunother 65(6): 651-662, 2016. PMID: 27020682. DOI: $10.1007 / \mathrm{s} 00262-016-1826-5$

23 Berntsson J, Svensson MC, Leandersson K, Nodin B, Micke P, Larsson AH, Eberhard J and Jirström K: The clinical impact of tumour-infiltrating lymphocytes in colorectal cancer differs by anatomical subsite: A cohort study. Int J Cancer 141(8): 16541666, 2017. PMID: 28677162. DOI: 10.1002/ijc.30869

24 Gregory AD and Houghton AM: Tumor-associated neutrophils: new targets for cancer therapy. Cancer Res 71(7): 2411-2416, 2011. PMID: 21427354. DOI: 10.1158/0008-5472.CAN-10-2583

25 Zahorec R: Ratio of neutrophil to lymphocyte counts - rapid and simple parameter of systemic inflammation and stress in critically ill. Bratisl Lek Listy 102(1): 5-14, 2001. PMID: 11723675.

26 Sato H, Tsubosa Y and Kawano T: Correlation between the pretherapeutic neutrophil to lymphocyte ratio and the pathologic response to neoadjuvant chemotherapy in patients with advanced esophageal cancer. World J Surg 36(3): 617-622, 2012. PMID: 22223293. DOI: $10.1007 / \mathrm{s} 00268-011-1411-1$

27 Josse JM, Cleghorn MC, Ramji KM, Jiang H, Elnahas A, Jackson TD, Okrainec A and Quereshy FA: The neutrophil-tolymphocyte ratio predicts major perioperative complications in patients undergoing colorectal surgery. Colorectal Dis 18(7): O236-O242, 2016. PMID: 27154050. DOI: 10.1111/codi.13373

28 Barbetta A, Nobel TB, Sihag S, Hsu M, Tan KS, Bains MS, Isbell JM, Janjigian YY, Wu AJ, Bott MJ, Jones DR and Molena D: Neutrophil to lymphocyte ratio as predictor of treatment response in esophageal squamous cell cancer. Ann Thorac Surg 106(3): 864-871, 2018. PMID: 29738752. DOI: 10.1016/j.athoracsur.2018.04.007

29 Chen MF, Tsai MS, Chen WC and Chen PT: Predictive value of the pretreatment neutrophil-to-lymphocyte ratio in head and neck squamous cell carcinoma. J Clin Med 7(10): 294, 2018. PMID: 30241364. DOI: $10.3390 /$ jcm7100294

30 Moldoveanu D, Pravongviengkham V, Best G, Martínez C, Hijal T, Meguerditchian AN, Lajoie M, Dumitra S, Watson I and Meterissian S: Dynamic neutrophil-to-lymphocyte ratio: a novel prognosis measure for triple-negative breast cancer. Ann Surg Oncol 27(10): 4028-4034, 2020. PMID: 32314154. DOI: 10.1245/s10434-020-08302-2

31 Guo J, Chen S, Chen Y, Li S and Xu D: Combination of CRP and NLR: a better predictor of postoperative survival in patients with gastric cancer. Cancer Manag Res 10: 315-321, 2018. PMID: 29491721. DOI: 10.2147/CMAR.S156071

32 Scheer RV, Fakiris AJ and Johnstone PA: Quantifying the benefit of a pathologic complete response after neoadjuvant chemoradiotherapy in the treatment of esophageal cancer. Int J Radiat Oncol Biol Phys 80(4): 996-1001, 2011. PMID: 20584580. DOI: 10.1016/j.ijrobp.2010.03.003

33 Rizk NP, Bach PB, Schrag D, Bains MS, Turnbull AD, Karpeh M, Brennan MF and Rusch VW: The impact of complications on outcomes after resection for esophageal and gastroesophageal junction carcinoma. J Am Coll Surg 198(1): 42-50, 2004. PMID: 14698310. DOI: 10.1016/j.jamcollsurg.2003.08.007

34 Lerut T, Moons J, Coosemans W, Van Raemdonck D, De Leyn P, Decaluwé H, Decker $G$ and Nafteux P: Postoperative complications after transthoracic esophagectomy for cancer of the esophagus and gastroesophageal junction are correlated with early cancer recurrence: role of systematic grading of complications using the modified Clavien classification. Ann Surg 250(5): 798-807, 2009. PMID: 19809297. DOI: 10.1097/ SLA.0b013e3181bdd5a8

Received January 18, 2022

Revised February 4, 2022

Accepted February 7, 2022 